Revisión

\title{
Principales aportes de la investigación del INIFAP a la nutrición porcina en México: retos y perspectivas
}

José Antonio Rentería Flores ${ }^{\mathrm{a}} \uparrow$

Sergio Gómez Rosales ${ }^{\text {a }}$

Luis Humberto López Hernández a

Gerardo Ordaz Ochoa ${ }^{a}$

Ana María Anaya Escalera ${ }^{a}$

César Augusto Mejía Guadarrama ${ }^{a}$

Gerardo Mariscal Landín ${ }^{a^{*}}$

${ }^{a}$ Instituto Nacional de Investigaciones Forestales Agrícolas y Pecuarias. Centro Nacional de Investigación en Fisiología y Mejoramiento Animal. km 1 Carretera a Colón, 76280 Ajuchitlán, Querétaro, México.

*Autor de Correspondencia: mariscal.gerardo@inifap.gob.mx

\section{Resumen:}

En esta revisión se hace una retrospectiva de las actividades de investigación realizadas en nutrición porcina por los investigadores del INIFAP en los 35 años de existencia del Instituto. El producto principal de esta actividad, ha sido el sentar las bases para una mejor alimentación del hato reproductor y del cerdo para abasto, enfocándola a resolver los problemas particulares de la porcicultura mexicana, con respecto al uso de las materias primas utilizadas en la alimentación del cerdo; así como la evaluación y mejora de la calidad de la canal, el enriquecimiento de la carne con metabolitos que incrementan su vida de anaquel y mejoran sus propiedades organolépticas. Asimismo, se hace una reflexión sobre los retos que enfrentará la nutrición porcina en el presente siglo, proponiendo las áreas que se tendrán que investigar para garantizar la sustentabilidad del sector, así como las acciones 
que los investigadores del programa y el INIFAP tendrán que realizar para responder adecuadamente a los desafíos a los que se enfrenta la porcicultura mexicana.

Palabras clave: Nutrición porcina, Retos, Aportes, INIFAP.

Recibido: $16 / 11 / 2020$

Aceptado: 22/03/2021

\section{Introducción}

La investigación en nutrición porcina es importante, ya que esta especie se caracteriza por su alta prolificidad, ciclo de producción corto y alta eficiencia alimenticia; características que han hecho que sea la carne más consumida a nivel mundial, representando el $36 \%$ del mercado $^{(1)}$, y la segunda a nivel nacional representando el $26 \%$ del consumo de carne en el país $^{(2)}$. En México la investigación pecuaria inició en 1947 al crearse el Instituto Pecuario, dependiente de la Secretaría de Agricultura y Ganadería; en 1962 se transformó en el Centro Nacional de Investigaciones Pecuarias (CNIP), el cual en 1968 se convirtió en el Instituto Nacional de Investigaciones Pecuarias (INIP), que al fusionarse en 1985 con los Institutos de Investigación Agrícola y Forestal dieron origen al Instituto Nacional de Investigaciones Forestales Agrícolas y Pecuarias (INIFAP). Los primeros cuatro artículos de nutrición porcina aparecieron en 1966; fueron publicados en el número 7 de la revista Técnica Pecuaria en México, revista creada en 1963 por el CNIP, la cual en 2010 se transformó en la Revista Mexicana de Ciencias Pecuarias. Desde ese momento hasta la fecha, el personal del Instituto ha realizado investigaciones que responden a las necesidades de la porcicultura nacional, ya sea generando la tecnología necesaria para el uso de materias primas en las diferentes fases productivas, o estudiando el impacto de la alimentación sobre la calidad del producto; así como el impacto de la alimentación en la eficiencia reproductiva y en la productividad del hato reproductor. Durante todo este periodo, la investigación realizada por el INIFAP ha contribuido al desarrollo de la porcicultura nacional y de su cadena de valor. En este manuscrito se resumen las principales aportaciones del INIFAP a la nutrición porcina y los retos a mediano y largo plazo a los que se enfrenta la investigación en el mundo y particularmente en México. Para la selección del material se consideró lo generado de 1985 a la fecha por investigadores del INIFAP, tanto en material impreso como digital, dando preferencia a los artículos científicos publicados y en segundo lugar las publicaciones en tesis y congresos. La información se organizó en la nutrición del hato reproductor y del cerdo para abasto, incluyendo desde el destete hasta finalización; así como el rendimiento en canal y la calidad de carne. 


\section{Hato reproductor}

El tamaño de la camada, el número de partos por cerda por año y el número de cerdos producidos durante la vida productiva de la cerda, son los parámetros que establecen las bases de la productividad y rentabilidad de una granja porcina. Los avances científicos y tecnológicos generados en las disciplinas de genética, nutrición, reproducción y salud animal han permitido incrementar estas variables durante los últimos 35 años.

\section{Situación actual}

En la mayoría de las explotaciones tecnificadas, se espera destetar 30 cerdos por hembra por año, y que la cerda produzca más de 70 cerdos al abasto, a lo largo de su vida productiva. En el caso de Dinamarca en particular, el número total de lechones destetados por camada se incrementó de 9.9 en 1996, a 12.2 en $2009^{(3)}$, mientras que en un reporte más reciente se menciona que el número de lechones destetados por camada para este país en 2017, fue de 14.6, lo que corresponde a 33.3 lechones destetados por cerda por año ${ }^{(4)}$.

La evaluación estadística de la producción porcina que se realiza en México está orientada al inventario de cerdos, a la producción por estado, a las importaciones y exportaciones, costos de insumos y materias primas, precio del cerdo en pie y de cortes primarios. Los pocos datos del análisis de la productividad del hato con que se cuenta en México, obedecen a reportes aislados de granjas en las que existen registros detallados del comportamiento. Ek-Mex et $a l^{(5)}$ al analizar la información de cuatro granjas comerciales, para cerdas de primero y segundo parto, encontraron variación en la cantidad de lechones nacidos vivos por cerda por año, presentando un rango entre 17.4 a 27.2 lechones. Por otro lado, Pérez Casillas ${ }^{(6)}$, presentó datos de cuatro granjas comerciales donde el promedio de lechones nacidos totales fue de 14.96, lechones nacidos vivos 13.59 y lechones destetados 11.58 , valores similares a los reportados por PigChamp en 2019, para las granjas de los Estados Unidos.

\section{Problemática}

Si bien el incremento en la eficiencia reproductiva ha significado una mayor rentabilidad para las explotaciones porcinas, también representa nuevos desafíos, entre los que destacan elaborar alimentos y esquemas de alimentación de precisión, que permitan expresar el potencial genético en los diferentes estados fisiológicos, mejorar su permanencia en el hato, manteniendo la sustentabilidad de las granjas porcinas.

El consumo inadecuado de nutrientes puede influenciar la respuesta reproductiva de diversas maneras; puede alterar el proceso de ovulación y retrasar el inicio de la pubertad en las cerdas jóvenes. La sobrealimentación en gestación provoca ganancia excesiva de peso, interfiere 
con el desarrollo normal de las glándulas mamarias, y tiene impacto negativo sobre la producción de leche y el consumo voluntario de alimento durante la lactación. El incremento en el tamaño de la camada y, por consiguiente, en la demanda de producción de leche, resultan en un déficit nutricional para la cerda lactante, lo cual puede alargar la duración del intervalo destete-estro, reducir la tasa ovulatoria y la calidad de los ovocitos liberados, así como el desarrollo de los cuerpos lúteos, durante el primer estro posdestete. Lo anterior probablemente resulte en una reducción en la habilidad de los embriones para desarrollarse y sobrevivir, impactando negativamente en el tamaño de la camada al parto subsiguiente. Estos problemas son una causa importante de desecho de animales, particularmente en las hembras jóvenes, porque dificultan mantener la integridad de los grupos de parición en la granja e inducen una reducción en el número de lechones producidos anualmente por cerda ${ }^{(7)}$.

\section{Alimentación de la cerda púber}

La alimentación de las cerdas de reemplazo durante su crecimiento influye sobre la edad a la que éstas inician su vida reproductiva (pubertad) y sobre el número de óvulos liberados (tasa ovulatoria) durante los primeros ciclos estrales, así como a la conformación de su estructura ósea, muscular y grasa. De acuerdo con investigaciones del INIFAP, la alimentación de cerdas de reemplazo debe de iniciar a partir de los $75 \mathrm{~kg} / 120$ días de edad, limitando la ganancia diaria de peso a $700 \mathrm{~g} /$ día, para ello se tiene que restringir el consumo de energía a $8 \mathrm{Mcal}$ de EM/día, utilizando un alimento con $0.78 \%$ de lisina digestible, y nivel de proteína no mayor a $17 \%(8)$.

\section{Alimentación de la cerda cíclica}

La nutrición influye sobre la función reproductiva de las cerdas, afectando particularmente la tasa de ovulación, pero existe poca información sobre el efecto específico de un déficit energético o proteico sobre la supervivencia embrionaria. Mejía-Guadarrama et $a l^{(9)}$ reportaron que, la restricción proteica en cerdas nulíparas ciclando disminuye las concentraciones plasmáticas de urea sin afectar la tasa de ovulación. Una mayor masa muscular materna al parto amortigua el impacto negativo de una restricción proteica moderada sobre la producción de leche ${ }^{(10)}$, pero cuando esta restricción es severa se tienen repercusiones en la reproducción ${ }^{(11-13)}$.

\section{Alimentación de la cerda gestante}

A nivel mundial, es preocupante la competencia entre la producción animal y los seres humanos por granos básicos, por lo que una de las líneas de investigación que el INIFAP ha desarrollado, es el utilizar ingredientes alternativos y estrategias nutricionales, que garanticen el aporte de nutrientes adecuados a la cerda gestante, aprovechando subproductos de la industria e insumos locales; convencionales y no convencionales. La alfalfa achicalada y los 
ensilados de maíz, sorgo o pastos, pueden ser utilizados como la ración completa de la cerda gestante; así mismo, la sustitución del $33.3 \%$ de sorgo por planta de yuca en harina ${ }^{(14)}$ o la adición de $3 \mathrm{~kg} / \mathrm{día}$ de ensilado de yuca ${ }^{(15)}$, mejora la ganancia de peso de la cerda durante el último tercio de gestación, siempre y cuando se fortifiquen con vitaminas, minerales, y suplementos proteicos ${ }^{(16-18)}$, asegurándose que, en el último tercio de gestación, se cubra el requerimiento de energía. Respecto al uso de melaza como fuente de energía, Ángeles y Cuarón ${ }^{(19)}$ reportan mayor vida productiva de la cerda y mejor productividad debido al uso de sustratos cetogénicos.

Al evaluar la adición de diferentes fuentes y niveles de fibra soluble e insoluble a la dieta de cerdas gestantes, se demostró que la composición de la fibra afecta de manera diferente la digestibilidad de energía y nitrógeno dietario ${ }^{(20)}$, por lo que es importante conocer el tipo de fibra que se está utilizando. El $78 \%$ de la variación en la digestibilidad de la energía en una dieta, podría ser explicado por el consumo de fibra soluble e insoluble: DIGAE= 88.74+0.083(CFS)- 0.02(CFIN); $\left(P<0.01 ; \mathrm{R}^{2}=0.78\right)$, donde: DIGAE es la digestibilidad aparente de energía, CFS es el consumo de fibra soluble en gramos y CFIN es el consumo de fibra insoluble en gramos. Rentería $e t a l^{(20)}$, demostraron que la inclusión de fibra insoluble disminuyó la digestibilidad aparente de energía en $0.2 \%$, y la digestibilidad aparente de nitrógeno en $0.1 \%$ con un consumo de fibra insoluble de $250 \mathrm{~g} /$ día equivalente a $13.5 \%$ de fibra insoluble en la dieta ${ }^{(21)}$. También se demostró que el consumo de fibra soluble no afectó la digestibilidad del nitrógeno, mientras que, la digestibilidad de la energía se relacionó positivamente al consumo de fibra soluble. Lo anterior significa que, es posible incluir altos niveles de fibra en la dieta de cerdas gestantes, sin comprometer su productividad, siempre que la influencia de la fibra en la digestibilidad de los nutrientes se considere en la formulación de la dieta y el cálculo de la ración diaria ${ }^{(22)}$. Además de que la inclusión de fibra en la dieta de la cerda gestante ayuda a mitigar el impacto de la restricción alimenticia a la que es sometida, y mejora el consumo de alimento en lactancia.

\section{Alimentación de la cerda en lactación}

En general, una disminución en el aporte energético durante la lactación no afecta la producción de leche, la cual es mantenida gracias a la movilización de las reservas corporales maternas ${ }^{(23)}$. Sin embargo, si la restricción energética es particularmente severa (6.5 vs 16.5 Mcal EM/día) el crecimiento de las camadas se reduce ${ }^{(24)}$.

Para la cerda en lactación, los aportes en aminoácidos se calculan en función del aporte en lisina, que es el primer aminoácido limitante. Los aportes proteicos son expresados en cantidad de proteína bruta o de lisina proporcionada en el alimento. Las camadas de cerdas sometidas a una restricción proteica durante la lactación (300-400 g de proteínas vs 700-900 $\mathrm{g} /$ día), mostraron reducción en su velocidad de crecimiento $^{(25)}$, especialmente a partir de la tercera semana de lactación ${ }^{(26)}$. La disminución en la velocidad de crecimiento de las camadas 
se debe a la reducción en la cantidad de leche producida, así como a una baja exportación de proteína y de lípidos en la leche de las cerdas racionadas ${ }^{(27)}$. Sin embargo, otros autores ${ }^{(10)}$, no observaron efectos significativos de una restricción proteica severa (350 a $410 \mathrm{~g}$ de proteína vs $830 \mathrm{~g}$ /día) sobre el crecimiento de las camadas y composición de la leche. Estos resultados contrastantes, podrían ser explicados a partir de las diferencias en el estado de reservas corporales de las cerdas al inicio de la lactación, ya que una mayor masa muscular materna al parto amortigua el impacto negativo de una restricción proteica sobre la producción de leche ${ }^{(10-12)}$. La producción de leche depende de la cantidad y calidad del alimento consumido durante la lactación, así como de la capacidad de las cerdas para movilizar sus reservas corporales. El nivel de ingestión de lisina y de energía metabolizable, interactúan para influenciar la producción láctea ${ }^{(28)}$.

La investigación realizada por el INIFAP en cerdas lactantes ha estado dirigida a mejorar el consumo de energía, aminoácidos, vitaminas y minerales, esenciales en esta fase, así como a desarrollar programas y técnicas de alimentación, que fomenten el consumo diario de alimento con la finalidad de minimizar la pérdida excesiva de peso, proteína y grasa corporal, para mejorar los parámetros reproductivos y disminuir la alta tasa de desecho ${ }^{(8)}$. Las investigaciones realizadas en el INIFAP muestran que la adición a la dieta de sacarosa, melaza $^{(19,29,30)}$, melaza-planta de yuca ${ }^{(15)}$ o picolinato de cromo $^{(31,32)}$, puede contribuir a disminuir parcialmente el problema de un bajo consumo voluntario de alimento y de una reducción en el tamaño de la camada al parto siguiente, lo anterior, siempre y cuando se considere el nivel de lisina de la dieta ${ }^{(33-35)}$, si bien la mejor estrategia para evitar esta problemática es evitar sobrealimentar a la cerda durante la gestación. La demanda de lisina digestible para la mayor productividad está entre 49 y $56 \mathrm{~g} /$ día $^{(21)}$. Al evaluar la concentración de lisina en la dieta ( 0.85 a $1.05 \%)$, en cerdas durante su primera lactancia, se reportaron ganancias de peso de la camada, superiores a $2.5 \mathrm{~kg} /$ día (peso de camada al destete a 21 días $\geq 67 \mathrm{~kg}$ ), cuando el consumo de lisina digestible fue $45 \mathrm{~g} /$ día, y se incrementó la respuesta hasta un consumo de lisina digestible de $66.2 \mathrm{~g} / \mathrm{día}^{(21)}$.

Con respecto al aporte de minerales en cerdas lactantes se ha investigado el selenio ( 0.2 a 0.3 ppm) por su relación con la producción, el uso de selenio "orgánico" es recomendable debido a su mejor distribución en tejidos periféricos ${ }^{(36)}$. Con respecto al aporte de vitaminas, se observó que la inclusión de $\beta$ caroteno $(250 \mathrm{mg} / \mathrm{kg}$ ) antes del primer servicio y durante la lactancia aumenta la supervivencia embrionaria ${ }^{(8)}$ y el uso de $4 \mathrm{mg} / \mathrm{kg}$ de $25-\mathrm{OH}-$ colecalciferol, contribuye a la solidez estructural y a la diferenciación celular en la actividad reproductiva ${ }^{(8)}$.

\section{Reinicio de la actividad sexual al destete}

La restricción nutricional durante la lactación puede influir sobre el desempeño reproductivo posdestete de la cerda, induciendo primeramente incremento en el intervalo destete-estro, y en el caso de que la cerda quede preñada, un aumento en la mortalidad embrionaria y una 
disminución en el tamaño de la camada al parto subsiguiente ${ }^{(28)}$. Diversos autores reportan una disminución del $39 \%$ en el número de folículos preovulatorios ( $\geq 7 \mathrm{~mm}$ de diámetro) durante los 3 a 4 días después del destete, en cerdas primerizas sometidas exclusivamente a una restricción proteica (aproximadamente $460 \mathrm{~g} /$ día), sugiriendo que la tasa ovulatoria de estas cerdas podría verse afectada negativamente ${ }^{(37)}$. Por su parte, Mejia-Guadarrama ${ }^{(10,11)}$ y Quesnel $^{(12)}$, establecieron que un déficit proteico durante la lactación, no afecta la supervivencia embrionaria, pero sí disminuye la tasa ovulatoria al primer estro posdestete en cerdas primerizas, a diferencia de lo encontrado por otros autores ${ }^{(38)}$. Esta discordancia probablemente se explique, al menos parcialmente, por la diferencia en la capacidad ovulatoria de las cerdas empleadas en estos trabajos 20 óvulos o más vs 12-15 óvulos, la cual podría acentuar el impacto negativo del déficit proteico sobre la tasa ovulatoria, en cerdas con un alto potencial ovulatorio.

\section{Nutrición del cerdo para abasto}

\section{Alimentación del lechón}

\section{Situación actual}

El destete es uno de los eventos más estresantes en la vida del cerdo, predisponiéndolo a desórdenes digestivos en el corto y mediano plazo, afectando negativamente su productividad y su sobrevivencia; en esta etapa se reportan niveles de mortalidad entre 6 y $20 \%{ }^{(39)}$. Dicha mortalidad está vinculada a diferentes factores de estrés asociados al destete, como cambio de alimento, ambiente, separación de su madre, la interacción con lechones de otras camadas y la presencia de agentes patógenos. El cambio de alimento es relevante, ya que, al sustituir la leche por un alimento sólido con diferentes fuentes y proporciones de nutrientes derivados de granos de cereales y pastas de oleaginosas, que contienen almidones y proteínas complejas que el lechón no digiere completamente, debido a que su capacidad digestiva no ha alcanzado la madurez suficiente para asimilarlos. Además, de que, en algunas ocasiones, estos ingredientes, pueden contener antígenos o factores anti nutricionales, lo que provoca menor digestibilidad del alimento sólido, dando lugar a diarreas, de tipo mecánico o infeccioso ${ }^{(40,41)}$.

Al destete los lechones se exponen a diferentes tipos de patógenos, algunos de los cuales forman parte de la microbiota normal del tracto digestivo. Asimismo, el sistema inmune asociado a la mucosa intestinal (innato y adaptativo), es inmaduro en lechones destetados entre los 21 y 28 días de edad, debido a los cambios que sufre la superficie de la mucosa intestinal derivados del destete. En esta etapa, también se elevan las concentraciones de cortisol en la sangre, lo que causa una inmunosupresión adicional ${ }^{(42,43)}$. Es por ello que los cerdos jóvenes son susceptibles a una serie de enfermedades bacterianas, que incluyen la 
colibacilosis causada por serotipos de Escherichia (E). coli enterotoxigénica y la salmonelosis causada por Salmonella $\operatorname{spp}^{(44)}$.

Por otro lado, los lechones muestran un consumo de alimento bajo y errático, lo que provoca retraso o la suspensión total de la motilidad estomacal, congestión de los vasos sanguíneos intestinales afectando su revestimiento con hemorragias y ulceraciones, edema e inflamaciones con presencia de células epiteliales inmaduras en la superficie de absorción. Esto conlleva al deterioro de la función protectora de la mucosa intestinal, debido a que la matriz proteica que se encuentra en los espacios intercelulares se debilita por la inflamación del intestino, aumentando la permeabilidad del epitelio ${ }^{(40,41)}$.

Después de algunas horas de ayuno y de sufrir hambre, los lechones pueden consumir alimento en cantidades superiores a su capacidad de digestión, lo que aunado a los cambios en la permeabilidad de la mucosa puede conducir a una digestión incompleta de los alimentos, provocando cambios osmóticos y de $\mathrm{pH}$ en el intestino, induciendo mayores secreciones hacia el lumen intestinal, lo que se traduce en aumento de la motilidad y la presencia de diarreas. Asimismo, los componentes alimenticios no digeridos pueden servir como sustrato para el crecimiento de microorganismos patógenos, aumentando la incidencia y severidad de las diarreas, lo que puede reflejarse en un retraso del crecimiento en el lechón ${ }^{(45)}$.

La duración y magnitud de la depresión del crecimiento causado por los factores mencionados, puede variar de 7 a 14 días, dependiendo de la edad y condición física del lechón al destete, la calidad del alimento, el programa alimenticio, el manejo ambiental y sanitario. Si bien, la mayoría de los lechones alcanzan a superar la recesión y continuar con su crecimiento, existe evidencia de que los cerdos que sufren retraso del crecimiento en esta etapa, depositan mayores cantidades de grasa subcutánea y menores cantidades de proteína en la canal en etapas posteriores, respecto a los cerdos que no fueron afectados en su crecimiento. De ello se infiere que la capacidad productiva posterior al destete es afectada por la magnitud de la reducción de la tasa de crecimiento posdestete.

Desde el punto de vista nutricional, para acortar el retraso del crecimiento posdestete, se requiere formular dietas con ingredientes altamente digestibles, y con los aportes de nutrientes adecuados al peso y edad de los animales, diseñar un programa de alimentación que considere el desarrollo digestivo del lechón, así como el uso de aditivos alimenticios que favorezcan la integridad de la mucosa. Resultando esto en mayor aprovechamiento de los alimentos y consecuentemente mejor desempeño productivo de los lechones. 


\section{Salud intestinal}

En cerdos, la salud intestinal y los criterios que la definen no se han esclarecido completamente ${ }^{(45,46)}$. El enfoque que normalmente se ha dado a la salud intestinal, ha estado dirigido a la prevención de enfermedades infecciosas, así como a mejorar la productividad de los animales, que incluye la utilización de nutrientes y el comportamiento productivo ${ }^{(47)}$. En los estudios sobre salud intestinal se han evaluado diferentes componentes de la barrera intestinal, sobresaliendo el epitelio de la mucosa, los componentes del sistema inmune y la microbiota, los cuales son interdependientes, y en conjunto con los factores dietéticos influyen de manera determinante en el desarrollo morfológico y funcional del aparato digestivo.

El bajo consumo de alimento causado por el destete provoca los cambios morfológicos y funcionales en el intestino descritos anteriormente; así como el acortamiento de las vellosidades, hiperplasia de las criptas, aumento de la mitosis y reciclaje de células epiteliales, disminuyendo por lo tanto la actividad enzimática del borde de cepillo y la capacidad de absorción. Los daños histológicos mencionados causan aumento en la permeabilidad paracelular, con mayor transporte de antígenos hacia la lámina propia, provocando inflamación. El consumo adecuado de alimento después del destete previene la pérdida de la función de barrera de las uniones estrechas localizadas en los espacios intercelulares, lo que indica la importancia de la presencia de nutrientes en el interior del intestino para mantener la función protectora del epitelio ${ }^{(44,47)}$. La pérdida de la integridad intestinal, también reduce el desarrollo de la actividad inmunológica innata al limitar su capacidad presentadora de antígenos, así como la liberación de citocinas y quimiocinas que regulan la respuesta inmunitaria local ${ }^{(48,49)}$.

Aunque la monocapa de enterocitos representa alrededor del $80 \%$ de las células epiteliales, el $20 \%$ restante del epitelio intestinal realiza otras tareas importantes y está constituido por: células caliciformes que secretan mucinas, células de Panneth que producen defensinas, células $\mathrm{M}$ que forman parte del sistema inmune entérico y células endocrinas que liberan hormonas y neuropéptidos. En estudios de salud intestinal, la producción y función de las mucinas han tenido un papel relevante debido a que los cambios en la cantidad, o composición del moco pueden conducir a deficiencia en la absorción de nutrientes o a la reducción de la función protectora de las mucinas ${ }^{(50)}$. La mucina intestinal 2 (MUC2), es una de las principales mucinas formadoras de gel, representa el componente primario de la barrera de las capas de moco, es un sitio donde reside la $\operatorname{IgA}$ secretora y es la primera línea de defensa que limita el contacto epitelial o la penetración de la microbiota y otros antígenos potencialmente peligrosos al organismo ${ }^{(51)}$. Las modificaciones en la secreción de mucinas y la respuesta inflamatoria resultante al destete, aumentan la susceptibilidad del lechón a sufrir infecciones bacterianas. 
El sistema inmune del cerdo destetado es inmaduro, por lo que su respuesta a la presencia de antígenos y agentes patógenos es deficiente. Algunos ejemplos de esto se observan en la función limitada de los linfocitos B y T durante las primeras semanas de vida, y las escasas respuestas específicas a antígenos en cerdos de menos de seis semanas, en comparación con los animales de mayor edad. Los linfocitos T se dividen en CD4 (colaboradores) y CD8 (citotóxicos), cuya función es establecer y maximizar las capacidades del sistema inmunitario; las células CD4 aparecen en la mucosa intestinal entre la tercera y cuarta semana de vida, mientras que las células T CD8 comienzan a aparecer en el epitelio entre las cuatro y seis semanas de edad. En cerdos al destete, se aumentan los linfocitos T CD4+ y CD8+ y se aumenta en el yeyuno, la expresión de citocinas pro-inflamatorias (TNF- $\alpha$, IL-1 $\beta$, IL-6 e IL-8) a los dos días posteriores al destete, debido a una inflamación intestinal transitoria.

La microbiota intestinal en los cerdos es muy dinámica y está sujeta a cambios con el tiempo, especialmente en la vida temprana. En el cerdo recién nacido la microbiota es modulada por la leche de las cerdas, y contiene una mayor abundancia de bacterias del tipo ácido láctico ${ }^{(39,52)}$. Sin embargo, al momento del destete se ha reportado la presencia de patógenos oportunistas en el interior del intestino delgado y grueso de los lechones, por lo que este reservorio de patógenos puede desencadenar la aparición de infecciones durante este período crítico conduciendo a la aparición de diarreas severas ${ }^{(53)}$. Inmediato al destete se reduce la abundancia relativa de Lactobacilos, y proliferan otro tipo de bacterias como Clostridium spp., Prevotella spp., Proteobacteriaceae y E. coli, resultando en una pérdida de la diversidad microbiana, esto como consecuencia del cese de la ingestión de leche y el inicio del consumo de alimento sólido ${ }^{(39,52)}$. La composición y diversidad de la microbiota intestinal de los cerdos a partir del destete, puede ser modificada por los niveles y fuentes de proteínas, azúcares o fibras dietéticas presentes en los alimentos iniciadores, además de los factores de manejo, ambientales y estatus sanitario de la granja ${ }^{(44,45,54)}$.

Por lo que para evitar alteraciones severas tanto en la integridad de la mucosa, como en la capacidad de respuesta inmune y la microbiota intestinal, es necesario el diseño de dietas especiales que aporten las cantidades y proporciones de nutrientes adecuadas a la edad y peso de los cerdos al destete, que incluyan ingredientes altamente digestibles pero también ingredientes convencionales que favorezcan una adecuada maduración del epitelio digestivo, y que faciliten la transición al uso de dietas menos complejas. Así mismo, en esta etapa se pueden incluir en la dieta aditivos dirigidos a mejorar la asimilación de los nutrimentos, aumentar la velocidad y efectividad de la respuesta inmune, así como para modular los cambios en la dinámica de las poblaciones microbianas durante el período de cambio del consumo de leche por el alimento sólido. Sin embargo, estas recomendaciones tendrán éxito en la medida en que sean acompañadas por estrategias y programas de alimentación que aseguren consumos adecuados de alimento en las etapas pre- e inmediatas al destete. 


\section{Aportaciones del INIFAP}

La relevancia de mantener altos consumos de alimento al destete a través de estrategias que induzcan la maduración de las capacidades digestivas de manera gradual, y con base a la presencia de los sustratos adecuados, se prioriza a la inducción de la maduración temprana de la actividad enzimática digestiva por medios farmacológicos ${ }^{(55,56)}$. Por esto, se han evaluado diferentes estrategias para inducir el consumo temprano de alimento sólido en lechones en lactancia y en el período inmediato al destete. Durante la lactancia, la introducción de un alimento preiniciador, a partir de los 14 días de edad, sirve de estímulo para que los cerdos empiecen a sensibilizarse al olor y textura de alimentos diferentes a la leche. Aunque el consumo de alimento sólido es bajo y variable en lechones lactantes, el uso de ingredientes como melaza y aceite, en especial si también se usan en los alimentos de las cerdas ${ }^{(57)}$, además de subproductos lácteos, pueden facilitar y acelerar el reconocimiento del alimento al destete. También durante la lactancia y los primeros días inmediatos al destete se recomienda ofrecer el alimento en pequeñas cantidades, pero de manera frecuente, con el fin de simular los hábitos de amamantamiento de lechones que en promedio amamantan cada 50 $\min ^{(58)}$. El mayor beneficio de alimentar "poco y frecuente" al destete se observa durante la primera semana postdestete $\mathrm{y}$, en especial es una práctica efectiva en la adaptación al consumo de dietas simples ${ }^{(59,60)}$.

Para diseñar alimentos que aporten las cantidades y proporciones de nutrientes adecuadas a la edad y peso de los cerdos al destete, se desarrolló una metodología para la canulación ileal de cerdos para evaluar la digestibilidad ileal, así como el impacto de diferentes ingredientes sobre las pérdidas endógenas de nutrientes ${ }^{(61)}$. A través de esta metodología se ha determinado la digestibilidad ileal de materia seca, proteína y energía de ingredientes como sebo de res y aceite de $\operatorname{coco}^{(62)}$, diferentes fuentes de lactosa ${ }^{(63)}$, cereales como avena, maíz y sorgos altos y bajos en taninos ${ }^{(64)}$, fuentes de proteína como concentrado de soya, aislado de soya y suero de leche ${ }^{(65)}$ y ajonjolí( ${ }^{(66)}$. La digestibilidad ileal aparente de aminoácidos se ha obtenido en pasta de soya y pasta de ajonjolíi ${ }^{(66,67)}$ pasta de canola ${ }^{(68)}$ caseína $^{(69)}$ y sorgo ${ }^{(70)}$. Además, se han determinado las pérdidas ileales endógenas de nitrógeno y aminoácidos usando como referencia la caseína ${ }^{(69,71)}$. También se han evaluado los cambios morfofisiológicos postdestete, como la histología de las vellosidades y la actividad de enzimas digestivas, asociados al uso de diferentes ingredientes alimenticios como cereales, incluyendo maíz, avena e híbridos de sorgo ${ }^{(72)}$, sorgos bajos y altos en taninos ${ }^{(73)}$, fuentes de proteína como ajonjolí y pasta de soya ${ }^{(74)}$, y concentrado de soya, aislado de soya y suero de leche ${ }^{(75)}$.

Otra área importante de estudio es el de la adición de probióticos y prebióticos a los alimentos, y el diseño de estos. El uso de dietas bajas en proteína combinadas con Bacillus (B). subtilis y B. licheniformis en cerdos al destete, permitió cambiar el patrón fermentativo de la microbiota intestinal aumentando la concentración de ácido acético, propiónico y 
butírico, y reduciendo la concentración de amoniaco en el intestino delgado y ciego, disminuyendo la incidencia y severidad de diarreas, y mejorando los parámetros productivos comparados con los cerdos que recibieron dietas altas en proteína más antibiótico ${ }^{(76)}$. La adición de ácido benzoico y una mezcla de $B$. subtilis y $B$. licheniformis en lechones al destete mantuvo los parámetros productivos, redujo los conteos de coliformes y la liberación de amoniaco en aguas residuales comparados con las respuestas de cerdos al destete alimentados con dietas que contenían antibióticos ${ }^{(77)}$. La suplementación con Saccharomyces (S.) cerevisiae y $S$. boulardii mejoró la altura de las vellosidades y redujo las concentraciones de citosinas pro-inflamatorias en el epitelio intestinal; el control de la inflamación intestinal y la preservación de la mucosa fue más efectiva con el uso de $S$. boulardii en lechones al destete $^{(52,78)}$. También el uso de concentrado de proteína de papa en lechones que consumieron dietas desprovistas de antibióticos, logró disminuir la severidad de las diarreas y se mantuvieron parámetros productivos comparados con lechones que recibieron alimentos adicionados con antibióticos ${ }^{(79)}$.

\section{Alimentación del cerdo en crecimiento-finalización}

\section{Situación actual}

La formulación moderna de alimentos para cerdos, en lo que respecta al aporte de macronutrientes, se basa en el uso de tres conceptos desarrollados en la segunda mitad del siglo pasado. El primero es el de proteína ideal, el cual se refiere a una proteína en la que todos los aminoácidos esenciales son co-limitantes para el rendimiento productivo del cerdo. Es decir, el suministro de aminoácidos coincide exactamente con su requerimiento y se toma como base al primer aminoácido limitante que en los cerdos es lisina. Este concepto teórico fue desafiado experimentalmente por el grupo inglés de Reading ${ }^{(80)}$. Actualmente ha sido modificado por diversos investigadores afinando cada vez más el perfil para las diferentes etapas productivas. El segundo es el uso en la formulación de raciones del contenido de energía neta de las materias primas, optimizando el uso de los nutrientes por parte del animal al disminuir el uso de la proteína dietética como fuente de energía; el desarrollo de este concepto fue realizado por Noblet y su equipo del INRA ${ }^{(81)}$. El tercero es el uso de la digestibilidad de los nutrientes.

La digestibilidad ileal de aminoácidos tuvo su apogeo en el último cuarto del siglo pasado ${ }^{(82)}$ y el tipo de coeficiente que se eligió para usarse en formulación fue el de digestibilidad ileal estandarizada que tiene dos características esenciales, la primera es su aditividad, aspecto esencial al formular una ración, ya que permite estimar de la mejor manera la cantidad del aminoácido que será utilizado metabólicamente por el animal. La otra característica es que su valor no está influenciado por el nivel de proteína de la dieta utilizada en su determinación, aspecto importante sobre todo para los cereales y materias primas bajas en proteína. El uso 
del contenido de fósforo digestible en la formulación de raciones comienza con el uso comercial de la enzima fitasa, ya que su empleo permite disminuir el uso de fósforo mineral en la dieta ${ }^{(83)}$, la implementación práctica de este concepto ha sido realizado por varios grupos de investigación. A principios de este siglo, estos tres principios de formulación fueron integrados en modelos capaces de predecir los requerimientos nutritivos ${ }^{(84,85)}$, lo que ha permitido el acercarse a la "Nutrición de Precisión", concepto que aplica los resultados de la investigación en nutrición y de ciencias afines, utilizando grandes bases de datos a través de la informática para predecir y proporcionar los requerimientos de nutrientes con la mayor precisión posible, buscando una producción eficiente segura y de alta calidad, además de asegurar el menor impacto posible al medio ambiente.

El uso conjunto de estos conceptos abrió la posibilidad de uso de nuevas materias primas y sub-productos de la industria, ya que potencializa su uso al estimar tanto su aporte nutricional, como su efecto sobre el crecimiento y la conformación de la canal del cerdo.

\section{Aportaciones del INIFAP}

El programa de investigación en Nutrición Porcina primeramente compiló información de los coeficientes de digestibilidad ileal estandarizada de diversas materias primas ${ }^{(86)}$; pero posteriormente el INIFAP contribuyó a la metodología de estudio de la digestibilidad ileal de los aminoácidos ${ }^{(61)}$, así como a la estimación de las pérdidas endógenas basales del nitrógeno y aminoácidos tanto en lechones como para cerdos en crecimiento ${ }^{(69,71)}$ lo que permitió generar información sobre los coeficientes de digestibilidad ileal estandarizada de los aminoácidos de los principales cereales utilizados en México: sorgo ${ }^{(87-89)}$, maíz ${ }^{(90)}$; y de diversas fuentes de proteína: pasta de ajonjolí ${ }^{(67)}$, de cártamo ${ }^{(91)}$, de canola ${ }^{(68,92)}$, gluten feed $^{(90)}$. En lo que respecta al uso del fósforo digestible, el INIFAP ha realizado investigación sobre el impacto del uso de la enzima fitasa sobre el incremento en la digestibilidad del fósforo de diversas materias primas ${ }^{(66,93,94)}$. También se realizaron estudios sobre el uso de aminoácidos cristalinos ${ }^{(95-98)}$ y sobre la adecuación nutricional que debe realizarse al utilizar moduladores metabólicos ${ }^{(99-101)}$; toda la investigación antes mencionada se enfocó a generar la información necesaria para optimizar el uso de las materias primas más utilizadas en el país y que en algunos casos son escasamente investigadas a nivel internacional.

En lo que respecta al uso de la energía dietética, el aporte del INIFAP consistió en estudios de balances de energía metabolizable ${ }^{(102,103)}$. Actualmente, el Instituto cuenta con las cámaras respiratorias para determinar en cerdos el contenido de Energía Neta de las dietas, lo que abre la posibilidad de realizar estudios sobre este tema. 


\section{Conformación de la canal y calidad de la carne}

La generación de canales porcinas de buena conformación, y con calidad, empieza con la selección de los progenitores ${ }^{(104)}$, del manejo correcto desde el destete hasta la finalización, e incluye los procedimientos adecuados durante la matanza y el manejo post-mortem de la carne. Al respecto, en algunos países existen sistemas de gradeo para canales porcinas, por ejemplo: USDA Pork Carcass Grading System en EUA; Pork Carcass Classification and Grading en Canadá; REGLAMENTO (CE) No 1249/2008 Unión Europea y la Norma Mexicana (NMX-FF-081-SCFI-2003) para la evaluación de Carne de Porcino en CanalCalidad de Carne-Clasificación, en México ${ }^{(105)}$. La finalidad de estos sistemas es facilitar el comercio y dar a los productores un sistema que permita calificar y pagar el precio justo por la canal.

La generación de la $\mathrm{NMX}^{(106)}$ fue el inicio de la evaluación objetiva de las canales porcinas en México. En general, los sistemas de gradeo obligan a la evaluación de estirpes completas, mediante la evaluación subjetiva y objetiva de los cortes primarios (después de su disección), y su correlación con los kilogramos producidos en pie o en canal (cantidad de magro) para generar modelos matemáticos ${ }^{(107)}$. En los modelos se han incluido factores como magro libre de grasa, contenido de grasa, mediciones de ultrasonografía en región dorsal y peso de canal caliente $^{(108)}$.

En los años 90 se generó información sobre la calidad de la carne obtenida de razas puras y de algunas cruzas ${ }^{(109)}$. En esos estudios, la raza Duroc predominantemente mostró mayor potencial productivo (ganancia diaria de peso) y calidad de carne (menor espesor de grasa dorsal, mayor grasa infiltrada, menor resistencia al corte, mayor jugosidad y terneza), por lo que actualmente es de las razas más utilizadas en los cruzamientos terminales.

Sin embargo, la evaluación de la calidad de carne a nivel industrial se complica, ya que, al buscar el menor daño en canales y cortes primarios, se hacen mediciones en sitios no representativos de la variabilidad, generando estudios deficientes; por ejemplo, al evaluar en la superficie ventral de lomos, cuando lo correcto debería ser realizar un corte transversal al músculo en el punto P2, a la altura de la décima costilla. El CENID Fisiología y Mejoramiento Animal, del INIFAP ha generado una serie de documentos de divulgación técnica-científica para ayudar a realizar estas evaluaciones de manera objetiva, los cuales pueden ser solicitados al siguiente correo: lopez.lhumberto@inifap.gob.mx.

Existen estudios en los que se revisaron los aspectos clave para producir carne de cerdo de calidad, en los cuales se consideró la interacción de las rutas metabólicas (gluconeogénesis, glucogenólisis, beta-oxidación y adipogénesis) y los sistemas antioxidantes endógenosexógenos en el animal ${ }^{(110-112)}$. Específicamente el impacto de los micronutrientes y de los procedimientos ante-mortem (ayuno, manejo), en la matanza (insensibilización) y 
posmortem ${ }^{(113)}$ tendrán incidencia en calidad de carne. Durante la transformación del músculo a carne, la glucólisis anaerobia juega un papel fundamental, por lo que el estudio del potencial glucolítico ${ }^{(114)}$ es determinante para poder explicar el $\mathrm{pH}$ final en la carne y su relación en poblaciones con los genes del Halotano y Rendement Napole ${ }^{(104,115)}$, con alta susceptibilidad a la generación de la carne pálida, suave y exudativa (PSE) y de carne ácida en el cerdo, respectivamente. La condición PSE caracteriza a la carne con bajo pH $(<5.5)$, baja capacidad de retención de agua (CRA) y un color pálido consecuencia del desjugado superficial. La CRA es una propiedad que describe la aptitud tecnológica de la carne y la carne PSE es consecuencia directa de un desbalance oxidativo a nivel membrana ${ }^{(116)}$. Con la finalidad de asegurar una alta CRA, se generaron diversas líneas de investigación en el CENID Fisiología y Mejoramiento Animal, en la que los minerales traza ${ }^{(117)}$, funcionando como cofactores de las enzimas antioxidantes endógenas: selenio en glutatión peroxidasa (GPx), hierro en catalasa y cobre en superóxido dismutasa, disminuyeron parcialmente los daños ocasionados por el estrés oxidativo, al reducir la pérdida de peso por goteo y mejorar el color. Sin embargo, los factores pro-oxidantes podrían ser mayores, por lo que, se buscaron alternativas con la vitamina $\mathrm{E}$ (antioxidante exógeno) suplementada en la dieta. La vitamina E reduce considerablemente las reacciones de oxidación medidas principalmente por la técnica de TBARS (Substancias Reactivas al Ácido 2-Tiobarbitúrico) que inciden en el color de la carne y la vida de anaquel ${ }^{(117,118)}$. Se ha comprobado que el uso de niveles adecuados de minerales traza y vitamina E provocan efectos positivos sobre la calidad de carne ${ }^{(119)}$.

En México, la investigación realizada en el CENID Fisiología y Mejoramiento Animal, recomienda reducir la dosis de minerales traza a partir de fuentes queladas ${ }^{(120)}$ y manejar valores de 120 UI de vitamina $\mathrm{E}$ (alfa-tocoferol acetato) por kilogramo de alimento en los últimos 42 días de la engorda ${ }^{(121,122)}$, sin detrimento de la productividad y calidad de la carne. Además, se han encontrado beneficios de otros micronutrientes, tal es el caso de 25hidroxicolecalciferol, metabolito secundario de la vitamina $\mathrm{D}_{3}$ con menor toxicidad, que al ser adicionado en la dieta, incide en la hiperplasia muscular durante el desarrollo de embriones con posibles efectos en la calidad de carne ${ }^{(123)}$, y una disminución de problemas de patas en cerdos de peso promedio a alto, favoreciendo el desempeño productivo al disminuir la cantidad de animales de bajo rendimiento, con efectos positivos en el color, CRA y textura de la carne ${ }^{(124,125)}$.

\section{Enriquecimiento de la carne}

El enriquecimiento de la carne es una cualidad finita, intrínseca a la genética y la región anatómica, pero fuertemente marcada por la nutrición, especialmente durante la etapa de finalización. Las moléculas ampliamente estudiadas para enriquecer la carne son los ácidos grasos de cadena larga, las vitaminas (básicamente las liposolubles) y los minerales traza. En adición, la Encuesta Nacional de Salud y Nutrición ENSANUT ${ }^{(126)}$ mediante sondeos y algunos muestreos en la última década, han identificado las deficiencias en vitaminas y 
minerales de la población mexicana, siendo los productos de origen animal los recomendados para resolverlas.

Hoy en día, la obtención de alimentos de origen animal enriquecidos con grasas de buena calidad, como los ácidos grasos omega 3 y 6 de cadena larga, son necesarios para la nutrición humana. En el cerdo, el perfil de lípidos depositado en la carne y grasa diferenciará a los productos enriquecidos con estos ácidos grasos de los no enriquecidos ${ }^{(127)}$. El uso de lípidos altamente oxidables junto con otros factores pro-oxidantes, como es la alta concentración de algunos minerales, pueden provocar un retraso en el crecimiento del cerdo ${ }^{(128)}$; por lo que se recomiendan dosis bajas de minerales, lo que se puede lograr usando fuentes queladas ${ }^{(120)}$. $\mathrm{Al}$ respecto, la investigación realizada por el INIFAP en torno al enriquecimiento de la carne de cerdo en los últimos años se ha enfocado en la modificación del perfil de lípidos (linoleico, linolénico, ácido docosahexaenoico) ${ }^{(129-131)}$, concentración de vitaminas (25-OHD3 y vitamina $\mathrm{E})^{(125,132,133)}$ y de minerales traza $(\mathrm{Se}, \mathrm{Zn}, \mathrm{Cu}, \mathrm{Mn}, \mathrm{Mg} \text { y Fe })^{(134,135)}$.

\section{Impactos del INIFAP}

Es difícil cuantificar el impacto que el INIFAP ha tenido en la producción porcina y en la sociedad mexicana a través de la investigación en nutrición porcina, ya que, las mejoras en la producción observadas en los últimos 35 años son producto de varios factores como la genética, alimentación-nutrición, reproducción, sanidad y manejo. Sin embargo, se puede resaltar que la investigación del INIFAP generó la primera norma mexicana de calidad de la canal y los criterios de calidad para la carne porcina producida en México. Asimismo, generó información sobre ingredientes no convencionales y la digestibilidad de varias de las materias primas más utilizadas en el país, lo que ha permitido su inclusión en los alimentos del cerdo. Sin embargo, se considera que el mayor impacto se ha logrado a través del convenio con la Universidad Nacional Autónoma de México (UNAM), en el que se han formado más de 170 Nutriólogos que actualmente se desempeñan en la industria, y se han realizado cursos de capacitación especializada a un gran número de agentes de cambio; además del papel preponderante que sus investigadores han tenido y tienen en las asociaciones gremiales que inciden en el sector como la Asociación Mexicana de Especialistas en Nutrición Animal (AMENA) y en la Asociación Mexicana de Veterinarios Especialistas en Cerdos (AMVEC).

\section{Retos}

La población mundial en la actualidad es de casi 7,500 millones, y se espera que para el año 2050 habrá más de 9,000 millones de personas; por lo que la FAO estima que el mundo tendrá que producir aproximadamente un 60 a $70 \%$ más de alimentos en los próximos 30 años. 
También se predice que la producción de proteína animal deberá de aumentar al menos tres veces y la producción de carne duplicarse para el año $2050^{(136)}$. Por lo que el desafío de la producción animal en general y de la porcicultura en particular en el siglo XXI, será el de producir de manera sostenible alimentos de origen animal en la cantidad y calidad adecuadas. El reto será producir esa cantidad de alimentos con recursos decrecientes año tras año, y de manera sustentable. Por lo anterior, los temas que adquieren relevancia y se deben de investigar son:

Uso de ingredientes alternativos: La incorporación de cereales y fuentes de proteína en la nutrición animal, que también son consumidos por el humano, crea una presión cada vez mayor en la industria pecuaria por crear o utilizar materias primas que no compitan directamente con el humano. Esta situación favorece el uso de subproductos y de nuevos productos como las fuentes de proteína de larvas, gusanos, algas, etc. El uso racional de esas materias primas dependerá de la generación de información a través de la investigación de la composición y digestibilidad de su proteína, del fósforo, del aporte de energía neta, así como del conocimiento sobre sus factores anti nutricionales o tóxicos.

Requerimientos nutricionales: La selección y el continuo mejoramiento genético produce animales con mayor velocidad de crecimiento y capacidad de deposición de proteína, características que modifican sus requerimientos nutricionales. Esta área de investigación tradicionalmente la han realizado los países desarrollados, donde la porcicultura se realiza en instalaciones cerradas con clima controlado, lo que hace que no necesariamente el conocimiento generado para estas condiciones, sea repetible para nuestro país; ya que en México la fase de crecimiento-engorda se realiza en instalaciones abiertas, con importantes variaciones climáticas en algunas estaciones del año, las cuales son capaces de modificar el comportamiento productivo de los animales, por lo que se requerirá realizar investigación en ese aspecto para ser capaces de adaptar los requerimientos nutritivos a la situación ambiental del país.

Salud intestinal: El destete está asociado con factores de estrés social, ambiental y nutricional, que pueden conducir a una reducción de la capacidad digestiva de los lechones y un retraso en su crecimiento. Los antibióticos se han utilizado en dosis sub-terapéuticas en las dietas de inicio con la finalidad de disminuir la presencia de diarreas severas y el impacto negativo del destete. Sin embargo, su uso como promotores del crecimiento ha sido prohibido, ya que favorece la presencia de bacterias resistentes a los antibióticos. Por lo que es necesario tener alternativas a su uso en la fase de destete cuando los animales son más susceptibles $^{(79)}$.

Mitigación del impacto climático: Se estima que la producción porcina emite 668 millones de toneladas de $\mathrm{CO}_{2}$-eq/año, o el $9 \%$ de las emisiones totales de la ganadería $^{(137)}$. Teóricamente, esta cantidad puede ser reducida al mejorar la eficiencia alimenticia al utilizar 
los criterios de formulación mencionados (proteína ideal, energía neta, aminoácidos y fósforo digestibles) y traducirlos a la nutrición de precisión. Estudios realizados muestran que, a través del uso de esos conceptos en la formulación de la dieta y programa alimenticio, se puede disminuir hasta un $22 \%$ la excreción de nitrógeno, que es el contaminante principal en las excretas porcinas, y a partir de él se forman los nitratos, el amoniaco y el óxido nitroso, el cual es el principal gas de efecto invernadero producido por la porcicultura.

Nuevos enfoques de la nutrición: Actualmente ha tomado importancia la interacción metabólica entre nutrientes y cómo afectan la expresión de genes específicos que pueden influir en el consumo de alimento, en el uso preferencial de los nutrientes hacia la deposición de proteína. También ha tomado importancia desde el punto de vista nutricional el impacto de la dieta sobre la microbiota intestinal, y cómo modula la relación nutriente-microbiota al metabolismo del animal, particularmente en el caso de lechones para disminuir la presencia de diarreas posdestete. Asimismo, se ha incrementado la investigación del uso de nutrientes por el organismo que impacte la producción del cerdo, como sería el uso funcional de algunos aminoácidos. Otro enfoque que ha adquirido importancia es el que a través de la alimentación se promueva el bienestar animal disminuyendo el estrés y conductas estereotipadas, sobre todo en el hato reproductor y en lechones destetados.

Productos biotecnológicos: La biotecnología ha sido definida como "cualquier aplicación tecnológica que utiliza sistemas biológicos, organismos vivos o derivados de los mismos, para hacer o modificar productos o procesos para un uso específico". Cada vez hay más productos biotecnológicos disponibles para la alimentación de los animales, como son: pro y prebióticos, aminoácidos cristalinos, enzimas exógenas, hormona del crecimiento, vitaminas, minerales traza quelados, etc. Cuyo uso, ha permitido aumentar la eficiencia en la producción, así como disminuir el impacto ambiental de la porcicultura.

\section{Del hato reproductor}

En cuanto a los retos y perspectivas en el corto, mediano y largo plazo, en una encuesta realizada en 2015, en Canadá, EUA, México, Brasil, Ecuador y Chile, para determinar los principales factores que inciden en la producción porcina, se encontró que los factores preponderantes hasta el 2015 eran las "Estrategias de Nutrición y Alimentación, la Bioseguridad, la Salud, así como aumentar el Volumen de Producción", siendo la eficiencia alimenticia y los lechones destetados por hembra por año, los principales factores en la producción porcina ${ }^{(138)}$. Las estrategias alimenticias empleadas durante el crecimiento de las cerdas de reemplazo pueden influenciar el desempeño reproductivo de éstas, a corto y largo plazo. Por ejemplo, a corto plazo es posible manipular la tasa ovulatoria y, a largo plazo, la cantidad y el tipo de reservas corporales, lo que puede tener una gran repercusión en la eficiencia reproductiva subsiguiente y en la longevidad de las cerdas. En particular, las estrategias alimenticias usadas durante la gestación y lactación, son factores importantes que 
inciden sobre el desempeño productivo de la hembra y pueden interactuar, en mayor o menor medida, con la alimentación que recibieron las cerdas durante su crecimiento.

\section{Conclusiones}

Debido a la gran diversidad de temas que se tienen que investigar y a la amplitud y diversidad de áreas de conocimiento involucradas (nutrición, reproducción, inmunología, microbiología, proteómica, metabolómica, etc.), así como los costos asociados al desarrollo de la investigación, es imperante la vinculación con diferentes instituciones y grupos de investigación tanto a nivel nacional (UNAM, Universidades Estatales, Colegio de Postgraduados, etc.) como internacional, que trabajen en temas de interés común. El fortalecimiento debe desarrollarse en dos vertientes. La primera es fortalecer la investigación conjunta a través de la formación de grupos interdisciplinarios e interinstitucionales, incluida la incorporación de nuevos investigadores al programa, el segundo es fortalecer la infraestructura física con que cuenta el INIFAP, la cual se concentra en el CENID Fisiología y Mejoramiento Animal (granja experimental y unidad metabólica); así como el fortalecimiento de los laboratorios institucionales de Nutrición, Calidad de Carne, Biología Molecular, Proteómica, y la creación del laboratorio de Metabolómica, lo que favorecería la realización de investigación de frontera en cerdos.

Obituario: Los autores deseamos expresar nuestro reconocimiento póstumo al Dr. José Antonio Rentería Flores fallecido el 17 de diciembre de 2020, quien siempre se caracterizó por su entrega al trabajo y su interés por la investigación, así como su activa participación en el desarrollo de esta publicación. Descanse en paz.

\section{Literatura citada:}

1. USDA. Ask USDA. Date acces: September 8th, 2020. https://ask.usda.gov/s/article/What-is-the-most-consumed-meat-in-theworld\#: :text=According\%20to\%20the\%20United\%20Nations,goats\%2Fsheep $\% 20$ $(5 \% 25)$.

2. Consejo Mexicano de la Carne. Compendio estadístico 2018. Consejo Mexicano de la Carne, Cd. de México. 2018.

3. Rutherford KMD, Baxter EM, Birgitte A, Peer P, D'Eath RB, Jarvis S, et al. The ethical and welfare implications of large litter size in the domestic pig: challenges and solutions. Danish Centre for Bioethics and Risk Assessment (CeBRA). 2011

4. Nielsen NP. Productivity is vital for sustainable pig production-the Danish experience. Adv Pork Prod. 2019. 
5. Ek-Mex JE, Segura-Correa JC, Alzina-López A. Efecto de la reducción o incremento del número de cerdos nacidos vivos en el segundo parto en la vida productiva de las cerdas en el sureste de México. Arch Med Vet 2016;48:243-246.

6. Pérez CJE. Cómo influye la nutrición en la estrategia para una producción eficiente de reemplazos porcinos. AMENA. 2020. 24 de agosto,. https://www.youtube.com/c/AMENAAC.

7. Lucia T, Dial GD, Marsh WE. Lifetime reproductive performance in female pigs having distinct reasons for removal. Livest Prod Sci 2000;63:213-222.

8. Mejía GCA, Cuarón IJA, Rentería FJA, Braña VD, Mariscal LG, Gómez RS. Alimentación del hato reproductor porcino. Colon, Qro., México: INIFAPSAGARPA, Libro científico No.1 2007.

9. Mejía-Guadarrama CA, Prunier A, Quesnel H. Dietary protein intake during oestrus cycle does not alter the ovulation rate in gilts. Repro Fert Develop 2004;16:589-597.

10. Mejia-Guadarrama CA, Pasquier A, Dourmad JY, Prunier A, Quesnel H. Protein (lysine) restriction in primiparous lactating sows: Effects on metabolic state, somatotropic axis, and reproductive performance after weaning. J Anim Sci 2002;80:3286-3300.

11. Mejía-Guadarrama CA, Pasquier A, Dourmand JY, Prunier A, Quesnel H. Les conséquences métaboliques et reproductives d'un rationnement protéique pendat la lactation variant-elles selon le poids vif des truies à la mise bas? . Journées Rech Por Fr 2003;35:141-148.

12. Quesnel H, Mejia-Guadarrama CA, Dourmad JY, Farmer C, Prunier A. Dietary protein restriction during lactation in primiparous sows with different live weights at farrowing: II. Consequences on reproductive performance and interactions with metabolic status. Repro Nutr Develop 2005;45:57-68.

13. Costermans N, Teerds KJ, Middelkoop A, Roelen B, Schoevers EJ, van Tol H, et al. Consequences of negative energy balance on follicular development and oocyte quality in primiparous sows. Biol Rep 2020;10:388-398.

14. López J, Loeza LR, Cuarón IJA. Utilización de la planta de yuca (Manihot esculenta c.) en la dieta para marranas. Téc Pecu Méx 1986;52:20-26.

15. López J, Cuarón IJA. Sistema de alimentación para cerdas reproductoras en el trópico con base en insumos regionales. XXIV Convención AMVEC. Morelia, Michoacán. 1989. 
16. Cuarón JA, Robles AAS. Empleo de alfalfa (Medicago sativa) deshidratada en la alimentación de cerdas gestantes. Téc Pecu Méx 1979;37:7-14.

17. Cuarón JA, Méndez V, Robles AAS. Valor del ensilaje de maíz en la alimentación de cerdas gestantes. Téc Pecu Méx 1980;39:13.

18. Ángeles MAA, Oliva HJ, López HZ, Cisneros GF, Loeza LR, Cuarón IJA. Efecto de la fuente de energía en la dieta para cerdas lactantes en dos zonas climáticas. Reunión Nacional de Investigación Pecuaria. Villahermosa, Tabasco. 1990:280-282.

19. Ángeles L, Cuarón IJA. Productividad y vida productiva en respuesta al tipo de suplemento energético durante el último tercio de gestación en cerdas alimentadas con forraje. Reunión Nacional de Investigación Pecuaria. 1990:348-350. Villahermosa, Tabasco.

20. Renteria-Flores JA, Johnston LJ, Shurson GC, Gallaher DD. Effect of soluble and insoluble fiber on energy digestibility, nitrogen retention, and fiber digestibility of diets fed to gestating sows. J Anim Sci 2008;86:2568-2575.

21. Rentería FJA, Merino B, Leyva MA, Soria A, Buenrostro FJ, Mejía GCA, et al. Respuesta de cerdas primerizas a la densidad de aminoácidos en la dieta de lactación. XII Congreso Bienal AMENA. Pto. Vallarta, Jalisco. 2005:25-28.

22. Renteria-Flores JA, Johnston LJ, Shurson GC, Moser RL, Webel SK. Effect of soluble and insoluble dietary fiber on embryo survival and sow performance. J Anim Sci 2008;86:2576-2584.

23. Noblet J, Etienne M. Effect of Energy Level in Lactating Sows on Yield and Composition of Milk and Nutrient Balance of Piglets. J Anim Sci 1986;63:18881896.

24. Koketsu Y, Dial GD, Pettigrew JE, Marsh WE, King VL. Influence of imposed feed intake patterns during lactation on reproductive performance and on circulating levels of glucose, insulin, and luteinizing hormone in primiparous sows. J Anim Sci 1996;74:1036-1046.

25. Mahan DC, Becker DE, Jensen AH. Effect of protein levels and opaque-2 corn on sow and litter performance during the first and second lactation periods. J Anim Sci $1971 ; 32: 470-475$.

26. Jones DB, Stahly TS. Impact of amino acid nutrition during lactation on body nutrient mobilization and milk nutrient output in primiparous sows. J Anim Sci 1999;77:15131522. 
27. King RH, Toner MS, Dove H, Atwood CS, Brown WG. The response of first-litter sows to dietary protein level during lactation. J Anim Sci 1993;71:2457-2463.

28. Tokach MD, Pettigrew JE, Dial GD, Wheaton JE, Crooker BA, Johnston LJ. Characterization of luteinizing hormone secretion in the primiparous, lactating sow: relationship to blood metabolites and return-to-estrus interval. J Anim Sci 1992;70:2195-2201.

29. Ángeles-Marín A, Oliva J, Cisneros F, Loeza R, Cuarón JA. Sow productive performance in response to lactation dietary energy source and environment. J Anim Sci 1990;68(Suppl: 1):366.

30. Oliva J, Cuarón JA, Villa A. Efecto del clima y de inclusión de melaza sobre el número de lechones nacidos en cerdas nulíparas. Téc Pecu Méx 1997;35:17-34.

31. Chárraga AS, Cuarón JA. Efecto de la adición de picolinato cromo y melaza en la dieta de cerdas multíparas durante un ciclo estral previo a la monta, sobre algunas características al parto. XXXIII Congreso AMVEC. Guanajuato, Guanajuato. 1998:49.

32. Chárraga AS, Rentería FJA, Cuarón JA. Efecto de la adición de picolinato cromo y melaza en la dieta de cerdas en lactación, durante 14 días previos al destete y hasta 24 días posteriores al servicio. XXXIII Congreso AMVEC.. Guanajuato, Guanajuato. 1998:51.

33. Rodríguez-Márquez MC, Cuarón JA. Dietary energy source on ovulation in swine. J Anim Sci 1990;68(Suppl: 1):367.

34. Cuarón JA, Chapple RP, Easter RA. Adición de lisina al sorgo durante el último tercio de gestación y suplementación de lisina durante la subsecuente lactación, a cerdas lactantes alimentadas con sorgo y pasta de ajonjolí. Téc Pecu Méx 1984;47:21-34.

35. Pérez-Mendoza V, Merino VB, Fakler TM, Cuarón JA. Cr-L-Metionina y obesidad en cerdas reproductoras. I Congreso CLANA y XI AMENA Cancún, México. 2003:373-374.

36. Lucero PM, Lanz GE, Cuarón JA. Eficacia relativa de dos fuentes de selenio. XIII Congreso Bienal AMENA. Pto. Vallarta, Jalisco. 2007:275.

37. Yang H, Pettigrew JE, Johnston LJ, Shurson GC, Walker RD. Lactational and subsequent reproductive responses of lactating sows to dietary lysine (protein) concentration. J Anim Sci 2000;78:348-357. 
38. King R, Williams IH. The effect of nutrition on the reproductive performance of first litter sows. 2. Protein and energy intakes during lactation. Anim Prod 1984;38:249256.

39. Xiong X, Tan B, Song M, Ji P, Kim K, Yin Y, et al. Nutritional intervention for the intestinal development and health of weaned pigs. Front Vet Sci 2019;6:1-14.

40. Reis de Souza TC, Mariscal LG, Escobar GK. Algunos factores fisiológicos y nutricionales que afectan las diarreas posdestete en lechones. Vet Méx 2010;41:275288.

41. Reis de Souza TC, Mariscal-Landín G, Escobar GKE, Aguilera BA, Magné BA. Cambios nutrimentales en el lechón y desarrollo morfofisiológico de su aparato digestivo. Vet Méx 2012;43:155-173.

42. Moeser AJ, Klok CV, Ryan KA, Wooten JG, Little D, Cook VL, et al. Stress signaling pathways activated by weaning mediate intestinal dysfunction in the pig. Am J Physiol Gastrointest Liver Physiol 2007;292:G173-G181.

43. Smith F, Clark JE, Overman BL, Tozel CC, Huang JH, Rivier JEF, et al. Early weaning stress impairs development of mucosal barrier function in the porcine intestine. Am J Physiol Gastrointest Liver Physiol 2010;298:G352-G363.

44. Kim JC, Hansen CF, Mullan BP, Pluske JR. Nutrition and pathology of weaner pigs: Nutritional strategies to support barrier function in the gastrointestinal tract. Anim Feed Sci Technol 2012;173:3-16.

45. Jayaraman B, Nyachoti CM. Husbandry practices and gut health outcomes in weaned piglets: A review. Anim Nutr 2017;3:205-211.

46. Roselli M, Pieper R, Rogel-Gaillard C, de Vries H, Bailey M, Smidt H, et al. Immunomodulating effects of probiotics for microbiota modulation, gut health and disease resistance in pigs. Anim Feed Sci Technol 2017;233:104-119.

47. Heo JM, Opapeju FO, Pluske JR, Kim JC, Hampson DJ, Nyachoti CM. Gastrointestinal health and function in weaned pigs: a review of feeding strategies to control post-weaning diarrhoea without using in-feed antimicrobial compounds. J Anim Physiol Anim Nutr 2013;97:207-237.

48. Van-der-Flier LG, Clevers H. Stem cells, self-renewal, and differentiation in the intestinal epithelium. Annu Rev Physiol 2009;71:241-260.

49. Pott $\mathrm{J}$, Hornef $\mathrm{M}$. Innate immune signalling at the intestinal epithelium in homeostasis and disease. EMBO Reports 2012;13:684-698. 
50. Wang W, Zeng X, Mao X, Wu G, Qiao S. Optimal dietary true ileal digestible threonine for supporting the mucosal barrier in small intestine of weanling pigs. $J$ Nutr 2010;140:981-986.

51. Honda K, Takeda K. Regulatory mechanisms of immune responses to intestinal bacteria. Mucosal Immunol 2009;2:187-196.

52. Mann E, Schmitz-Esser S, Zebeli Q, Wagner M, Ritzmann M, Metzler-Zebeli BU. Mucosa-associated bacterial microbiome of the gastrointestinal tract of weaned pigs and dynamics linked to dietary calcium-phosphorus. PLOS-ONE 2014;9:1-13.

53. Gresse R, Durand FC, Dunière L, Blanquet-Diot S, E F. Microbiota composition and functional profiling throughout the gastrointestinal tract of commercial weaning piglets. Microorganisms 2019;7:343.

54. Everaert N, Van Cruchten S, Weström B, Bailey M, Van Ginneken C, Thymann T, et al. A review on early gut maturation and colonization in pigs, including biological and dietary factors affecting gut homeostasis. Anim Feed Sci Technol 2017;233:89103.

55. Gómez RS, Angeles ML, Cuarón IJA. Efecto de la edad al destete, calidad de la dieta y tratamiento con dexametasona en la respuesta productiva de lechones. Téc Pecu Méx 1994;32:124-133.

56. Gómez S, Angeles ML, Cuarón JA. Growth performance and enzyme development in weanling pigs injected with dexamethasone. J Anim Sci 1997;75:993-1000.

57. Cisneros GF, Gómez RS, Angeles MAA, Loeza LR, Cuarón IJA. Efecto del tipo de alimento consumido por el lechón en lactancia sobre el comportamiento productivo al destete con diferentes dietas. XXVI Congreso Nacional AMVEC. Mérida, Yucatán. 1991:83.

58. Cisneros GF, Angeles MAA, Cuarón IJA, Santos DPJ. Hábitos de amamantamiento de lechones en clima tropical Téc Pecu Méx 1989;27:91-95.

59. Mojica-Enríquez C, Robles A, Cuaron JA. Diet formulation and feeding frequency in weanling pigs [Abstract] . J Anim Sci 1991;69((Suppl: 1)):385.

60. Gómez RS, Cuarón JA. Comportamiento productivo de lechones en función del peso al destete y del sistema de alimentación. XIV Congreso Panamericano de Ciencias Veterinarias PANVET. Acapulco, Guerrero. 1994:242.

61. Reis de Souza TC, Mar BB, Mariscal LG. Canulación de cerdos posdestete para pruebas de digestibilidad ileal: Desarrollo de una metodología. Téc Pecu Méx 2000;38:143-150. 
62. Reis de Souza TC, Mariscal LG, Uribe LL. Efecto de la fuente de grasa sobre el comportamiento zootécnico y la digestibilidad total e ileal de los nutrimentos en lechones destetados. Téc Pecu Méx 2001;39(3):193-206.

63. Reis de Souza TC, Mariscal LG, Aguilera BA. Empleo de dos fuentes de lactosa en la dieta de lechones y sus efectos en el aparato digestivo. Téc Pecu Méx 2002;40(3):299-308.

64. Reis de Souza TC, Mariscal LG, Barreyro AA. Efecto de diferentes cereales en dietas de iniciación para lechones sobre la digestibilidad de los nutrimentos y la preferencia alimentaria. Vet Méx 2005;36(1):11-24.

65. Aguilera MAB, Reis de Souza TC, Mariscal LG, Borbolla AGS, Aguilera AB. Digestibilidad de nutrimentos en lechones alimentados con dietas con aislado o concentrado de proteína de soya. Téc Pecu Méx 2006;44(3):301-311.

66. Reis de Souza TC, Escobar García K, Aguilera AB, Ramirez RE, Mariscal-Landín G. Sesame meal as the first protein source in piglet starter diets and advantages of a phytase: a digestive study. S Afr J Anim Sci 2017;47:606-615.

67. Aguilera A, Reis de Souza TC, Mariscal-Landín G, Escobar K, Montaño S, Bernal MG. Standardized ileal digestibility of proteins and amino acids in sesame expeller and soya bean meal in weaning piglets. J Anim Physiol Anim Nutr 2015;99:728-736.

68. Mariscal-Landín G, Reis de Souza TC, Parra SJE, Aguilera BA, Mar BB. Ileal digestibility of protein and amino acids from canola meal in weaned piglets and growing pigs. Livest Sci 2008;116:53-62.

69. Mariscal-Landín G, Reis de Souza TC. Endogenous ileal losses of nitrogen and amino acids in pigs and piglets fed graded levels of casein. Arch Anim Nutr 2006;60:454466.

70. Mariscal-Landín G, Reis de Souza TC, Ávalos MA. Ileal amino acids digestibility of sorghum in weaned piglets and growing pigs. Animal 2010;4:1341-1348.

71. Reis de Souza TC, Aguilera BA, Mariscal-Landín G. Estimation of endogenous protein and amino acid ileal losses in weaned piglets by regression analysis using diets with graded levels of casein. J Anim Sci Biotechnol 2013;4:36.

72. Reis de Souza TC, Guerrero MJC, Barreyro AA, Mariscal LG. Efecto de diferentes cereales sobre la morfología intestinal de lechones recién destetados. Téc Pecu Méx 2005;43:309-321. 
73. Gómez-Soto JG, Aguilera AB, Escobar GK, Mariscal-Landín G, Reis de Souza TC. Efecto del nivel de taninos del sorgo y del día posdestete sobre algunas características morfofisiológicas del aparato digestivo de lechones. Arch Latinoam Prod Anim 2015;23:63-70.

74. Aguilera BA, Reis de Souza TC, Mariscal-Landín G, Guerrero CMJ, Escobar GK, Bernal SMG, et al. Morphophysiological adaptations of the gastrointestinal tract in piglets fed a sesame meal or soybean meal diet. Am J Anim Vet Sci 2014;9:28-35.

75. Souza TCR, Aguilera MBA, Aguilera AB, Mariscal GL, Guerrero MJC. Morfología del tracto digestivo de lechones alimentados con dietas con aislado o concentrado de proteínas de soya. Arch Latinoam Prod Anim 2007;15(4):135-141.

76. Escobar GK, Reis de Souza TC, Mariscal-Landín G, Aguilera BA, Bernal SMG, Gómez SJG. Microbial fermentation patterns, diarrhea incidence, and performance in weaned piglets fed a low protein diet supplemented with probiotics. Food Nutr Sci 2014;5:1776-1786.

77. Pérez AMA, Cervantes LJ, Braña VD, Mariscal-Landín G, Cuarón IJA. Ácido benzoico y un producto basado en especies de Bacillus para proteger la productividad de los lechones y al ambiente. Rev Mex Cienc Pecu 2013;4:447-468.

78. Bautista-Marín S, Escobar-García K, Molina-Aguilar C, Mariscal-Landín G, Aguilera-Barreyro A, Díaz-Muñoz M, et al. Antibiotic-free diet supplemented with live yeasts decreases inflammatory markers in the ileum of weaned piglets. S Afr J Anim Sci 2020;50:353-365.

79. Reis de Souza TC, Aguilera BA, Rubio RS, Machado GY, Escobar GK, Gómez-Soto $\mathrm{JG}$, et al. Growth performance, diarrhoea incidence, and nutrient digestibility in weaned piglets fed an antibiotic-free diet with dehydrated porcine plasma or potato protein concentrate. Annals Anim Sci 2019;19:159-172.

80. Fuller MF, McWilliam R, Wang TC, Giles LR. The optimum dietary amino acid pattern for growing pigs 2. Requirements for maintenance and for tissue protein accretion. Br J Nutr 1989;62:255-267.

81. Noblet J, Fortune H, Dupire C, Dubois S. Digestible, metabolizable and net energy values of 13 feedstuffs for growing pigs: effect of energy system. Anim Feed Sci Technol 1993;42:131-149.

82. Furuya S, Kaji Y. Additivity of the apparent and true digestible amino acid supply in barley, maize, wheat or soya bean based diets for growing pigs. Anim Feed Sci Technol 1991;32:321-331. 
83. Jongbloed AW, Everts H, Kemme PA, Meroz Z. Quantification of absorbability and requirements of macroelements. In: Kyriazakis I editor. A quantitative biology of the pig. Wallingford Oxon UK: CABI Publishing; 1999:275-298.

84. van Milgen J, Valancogne A, Dubois S, Dourmad JY, Sève B, Noblet J. InraPorc: A model and decision support tool for the nutrition of growing pigs. Anim Feed Sci Technol 2008;143.

85. NRC. Nutrient requirements of swine: Eleventh revised edition. Washington, DC: The National Academies Press; 2012.

86. Mariscal LG, Ávila E, Tejada I, Cuarón IJA, Vásquez C. Tablas del contenido de aminoácidos totales y de los coeficientes de digestibilidad verdadera para aves y cerdos. Tablas del contenido de aminoácidos totales y de los coeficientes de digestibilidad verdadera para aves y cerdos. Querétaro, México: INIFAP-Publicación Especial; 1997.

87. Reis de Souza TC, Ávila AIE, Ramírez RE, Mariscal-Landín G. Effects of kafirins and tannins concentrations in sorghum on the ileal digestibility of amino acids and starch, and on the glucose and plasma urea nitrogen levels in growing pigs. Livest Sci 2019;227:29-36.

88. Mariscal-Landín G, Avellaneda JH, Reis de Souza TC, Aguilera A, Borbolla GA, Mar BB. Effect of tannins in sorghum on amino acid ileal digestibility and on trypsin (E.C.2.4.21.4) and chymotrypsin (E.C.2.4.21.1) activity of growing pigs. Anim Feed Sci Technol 2004;117:245-264.

89. Balderrama-Pérez VA, Gómez-Soto JG, Reis de Souza TC, Ramírez RE, MariscalLandín $\mathrm{G}$. Is the kafirin profile capable of modulating the ileal digestibility of amino acids in a soybean meal-sorghum diet fed to pigs? Anim Nutr 2019;5:124-129.

90. Mariscal-Landín G, Reis de Souza TC, Ramírez RE. Effects of corn gluten feed inclusion at graded levels in a corn-soybean diet on the ileal and fecal digestibility of growing pigs. J Anim Sci Biotechnol 2014;5:40.

91. Mariscal-Landín G, Ramírez RE, Cuarón IJA. Valor nutritivo de subproductos de cártamo para cerdos en finalización. Rev Mex Cienc Pecu 2017;8:331-340.

92. Mariscal-Landín G, Ramirez RE. Determinación de la digestibilidad de la proteína, aminoácidos y energía de canola integral en cerdos en crecimiento. Rev Mex Cienc Pecu 2017;8:297-304. 
93. Ávalos CMA, Gómez RS, Ángeles ML, Braña VD, Mariscal-Landín G, Cuarón IJA. Fitasa y enzimas fibrolíticas en dietas para cerdos con diferentes sustratos. Rev Mex Cienc Pecu 2011;2:117-135.

94. Soria-Flores AI, Mariscal-Landín G, Gómez RS, Cuarón IJA. Efecto de la adición de enzimas fibrolíticas y una fitasa para cerdos en crecimiento sobre la digestibilidad de nutrientes. Téc Pecu Méx 2009;47:1-14.

95. Kerr BJ, Kidd MT, Cuaron JA, Bryant KL, Parr TM, Maxwell CV, et al. Isoleucine Requirements and Ratios in Starting (7 to 11 Kg) Pigs. J Anim Sci 2004;82:23332342.

96. Kerr BJ, Kidd MT, Cuaron JA, Bryant KL, Parr TM, Maxwell CV, et al. Utilization of Spray-Dried Blood Cells and Crystalline Isoleucine in Nursery Pig Diets. J Anim Sci 2004;82:2397-2404.

97. Sierra DJ, Cuarón IJA. Formulación a un perfil ideal de aminoácidos en base total o digestible, para cerdos en crecimiento. Reunión Nacional de Investigación Pecuaria. Ciudad de México. 1995:287.

98. Castañeda EO, Sierra DJ, Cuarón IJA. Lisina en función de la proteína, cuando se formula a un perfil ideal, para cerdos en crecimiento. Reunión Nacional de Investigación Pecuaria. Ciudad de México. 1995:289.

99. Braña VD, Rojo-Gómez GA, Ellis M, Cuarón JA. Effect of gender (gilt and surgically and immunocastrated male) and ractopamine hydrochloride supplementation on growth performance, carcass, and pork quality characteristics of finishing pigs under commercial conditions. J Anim Sci 2013;91:5894-5904.

100. Mariezcurrena-Berasain MA, Braña-Varela D, Mariezcurrena-Berasain MD, Domínguez-Vara IA, Méndez-Medina D, Rubio-Lozano MS. Características químicas y sensoriales de la carne de cerdo, en función del consumo de dietas con ractopamina y diferentes concentraciones de lisina. Rev Mex Cienc Pecu 2018;3:427437.

101. Ángeles ML, Loeza R, Cuarón JA, Robles A, Moore P. Respuesta a la somatotropina en cerdos en finalización en dos localidades. Reunión Nacional de Investigación Pecuaria. Guadalajara, Jalisco. 1993:118.

102. Mariscal-Landín G, Reis de Souza TC, Ramírez RE. Metabolizable energy, nitrogen balance, and ileal digestibility of amino acids in quality protein maize for pigs. J Anim Sci Biotechnol 2014;5:26. 
103. Vázquez ME, Reis de Souza TC, Ramírez RE, Mariscal-Landín G. Impacto del peso al nacimiento del lechón sobre los balances de nitrógeno y energía en la fase de crecimiento. Rev Mex Cienc Pecu 2019;10:903-916.

104. Ellis M, McKeith FK, Miller KD. The effects of genetic and nutritional factors on pork quality - Review. Asian-Aus J Anim Sci 1999;12:261-270.

105. NMX-FF-081-SCFI. Productos Pecuarios-Carne de Porcino en Canal-Calidad de la Carne-Clasificación. Productos Pecuarios-Carne de Porcino en Canal-Calidad de la Carne-Clasificación. México: Normas Mexicanas, Secretaría de Economía,; 2003:114.

106. NMX-FF-081-SCFI. Productos Pecuarios. Carne de Cerdo en Canal. Clasificación. (CANCELADA). Productos Pecuarios. Carne de Cerdo en Canal. Clasificación. (CANCELADA). México: Normas Mexicanas, Secretaría de Economía.; 1993:1-10.

107. Miar Y, Plastow GS, Moore SS, Manafiazar G, Charagu P, Kemp RA, et al. Genetic and phenotypic parameters for carcass and meat quality traits in commercial crossbred pigs. J Anim Sci 2014;92:2869-2884.

108. Cisneros F, Ellis M, Miller KD, Novakofski J, Wilson ER, McKeith FK. Comparison of transverse and longitudinal real-time ultrasound scans for prediction of lean cut yields and fat-free lean content in live pigs. J Anim Sci 1996;74:2566-2576.

109. NPPC. Genetic Evaluation: Terminal Line Program Results. Genetic Evaluation: Terminal Line Program Results. National Pork Producers Council; 1995:312 pag.

110. Scheffler TL, Gerrard DE. Mechanisms controlling pork quality development: The biochemistry controlling postmortem energy metabolism. Meat Sci 2007;77(1):7-16.

111. Rosenvold K, Andersen HJ. Factors of significance for pork quality - a review. Meat Sci 2003;64:219-237.

112. Fernández-Dueñas DM, Mariscal G, Ramírez E, Cuarón JA. Vitamin C and bcarotene in diets for pigs at weaning. Anim Feed Sci Technol 2008;146:313-326.

113. Faucitano L. Invited review: Effects of lairage and slaughter conditions on animal welfare and pork quality. Can J Anim Sci 2010;90(4):461-469.

114. Bertol TM, Braña VD, Ellis M, Ritter JM, Peterson AB, Mendoza FO, et al. Effect of feed withdrawal and dietary energy source on muscle glycolytic potential and blood acid-base responses to handling in slaughter-weight pigs. J Anim Sci 2011;89:15611573. 
115. Mckeith FL, Ellis M, Miller KD, Sutton DS, Mckeith FK. The effect of RN genotype on pork quality. Reciprocal Meat Conf Proc. 1998:118-124.

116. Honikel KO, Kim CJ. Causes of the development of PSE pork. Fleischwirtschaft 1986;66:349-353.

117. Mahan DC, Kim YY. The role of vitamins and minerals in the production of high quality pork - Review. Asian-Aus J Anim Sci 1999;12:287-294.

118. Jensen C, Lauridsen C, Bertelsen G. Dietary vitamin E: Quality and storage stability of pork and poultry. Trends Food Sci Technol 1998;9:62-72.

119. Flohr JR, Derouchey JM, Woodworth JC, Tokach MD, Goodband RD, Dritz SS. A survey of current feeding regimens for vitamins and trace minerals in the US swine industry. J Swine Health Prod 2016;Nov-Dec:290-303.

120. González M, López HLH, Pettigrew J, Cuarón IJA. Niveles de minerales orgánicos $(\mathrm{Cu}, \mathrm{Fe}, \mathrm{Mn}$ y $\mathrm{Zn})$ en el crecimiento y finalización de cerdos. VII Congreso Latinoamericano de Nutrición Animal Cancún, México. 2016:1.

121. López HLH, Fridstein GFU, Cuarón IJA. Validación de la suplementación de 120 UI de vitamina E en cerdos: niveles sanguíneos y calidad de carne. XIX Congreso Bienal AMENA. Pto. Vallarta, Jalisco. 2019:63.

122. López HLH, Pérez AA, Cuarón IJA. Vitamina E para proteger el crecimiento de los cerdos y la calidad de su carne. VII Congreso Latinoamericano de Producción Animal. Cancún, México. 2016:1.

123. Duffy SK, Kelly AK, Rajauria G, Jakobsen J, Clarke LC, Monahan FJ, et al. The use of synthetic and natural vitamin D sources in pig diets to improve meat quality and vitamin D content. Meat Sci 2018;143:60-68.

124. Guerrero HD, Pérez AMA, López HLH, Candanosa AIE, Cuarón IJA. Dos niveles de vitaminas y la adición de 25OHD3 en dietas para cerdos. XVIII Congreso Bienal AMENA. Pto. Vallarta, Jalisco. 2017.

125. Calderon M, González M, López HLH, Braña VD, Cuarón IJA. Enriquecimiento de la dieta de finalización de cerdos con altas dosis de 25-hidroxicolecalciferol para proteger la calidad de carne. XVII Congreso Bienal AMENA. Pto. Vallarta, Jalisco. 2015. 
126. Secretaría de Salud, Instituto Nacional de Salud Pública, Instituto Nacional de Estadística y Geografía. "Encuesta Nacional de Salud y Nutrición 2018," Presentación de resultados, Consultado 1 Sep, 2020. https://ensanut.insp.mx/encuestas/ensanut2018/doctos/informes/ensanut_2018_pres entacion_resultados.pdf.

127. Woods VB, Fearon AM. Dietary sources of unsaturated fatty acids for animals and their transfer into meat, milk and eggs: A review. Livest Sci 2009;126:1-20.

128. Dove CR, Ewan RC. Effect of excess dietary copper, iron or zinc on the tocopherol and selenium status of growing pigs. J Anim Sci 1990;68:2407-2413.

129. Valdés-Reyez J. Impacto de la calidad de la grasa en la dieta de las cerdas reproductoras y sus consecuencias en producción. [tesis maestría]. Cd. de México: UNAM; 2016.

130. Sanchez-Piñeyro S. Uso de una fuente de dha proveniente de algas marinas en la alimentación de cerdos en crecimiento y finalización: evaluación de la calidad de carne y grasa. [tesis licenciatura]. Cd. de México: UNAM; 2018.

131. Calderón M, López H, Morales R, Castañeda G, Cuarón IJA. Aplicación de un suplemento natural de metabolitos de colina como aditivo en dietas para cerdos en crecimiento y finalización. VII Congreso Latinoamericano de Nutrición Animal. Pto. Vallarta, Jalisco. 2016.

132. Guerrero-Huerta D. Resultado de un ajuste a los niveles de vitaminas en dietas para cerdos en crecimiento. [tesis licenciatura]. Cd. de México: UNAM; 2018.

133. Garrido-Monroy B. Efecto de la suplementación de vitamina D3 y 25hidroxicolecalciferol en la calidad microbiológica y estabilidad oxidativa de carne de cerdo. [tesis licenciatura]. UNAM; 2013.

134. González-Mendoza M. Efecto de la fuente de minerales en la protección antioxidante de la carne y la regulación de proteínas asociadas a estrés durante el sacrificio y la transformación de músculo a carne en cerdos. [tesis maestría]. Cd. de México: UNAM; 2018.

135. López-Rios F. Contenido y biodisponibilidad de minerales traza ( $\mathrm{Cu}, \mathrm{Fe}, \mathrm{Mn}$ y Zn) en la carne de cerdo. [tesis licenciatura]. Cd. de México: UNAM; 2018.

136. Babinszky L, Verstegen MWA, Hendriks WH. Challenges in the 21st century in pig and poultry nutrition and the future of animal nutrition. In: Hendriks WH, et al, editors. Poultry and pig nutrition, challenges of the 21st century. First ed. Wageningen, The Netherlands: Wageningen Academic Publishers; 2019:17-37. 
137. McAuliffe GA, Takahashi T, Mogensen L, Hermansen JE, Sage CL, Chapman DV, et al. Environmental trade-offs of pig production systems under varied operational efficiencies. J Cleaner Prod 2017;165:1163-1173.

138. Córdoba DJ. Tendencias hacia el año 2025 sobre los principales factores que inciden en la producción en la industria en América. Congreso AMVEC- Veracruz, México. 2016. 